\title{
Effect of vitamin D3 on bone turnover markers in critical illness: post hoc analysis from the VITdAL-ICU study
}

\author{
V. Schwetz ${ }^{1}$ (D) C. Schnedl ${ }^{2} \cdot$ T. Urbanic-Purkart ${ }^{3} \cdot$ C. Trummer $^{1}$ - H. P. Dimai ${ }^{1}$ \\ A. Fahrleitner-Pammer ${ }^{1}$. C. Putz-Bankuti ${ }^{5}$ K. B. Christopher ${ }^{6}$. \\ B. Obermayer-Pietsch ${ }^{1}$ - T. R. Pieber ${ }^{1}$ H. Dobnig ${ }^{1,4} \cdot$ K. Amrein ${ }^{1}$
}

Received: 15 May 2017 / Accepted: 2 August 2017 /Published online: 25 August 2017

(C) The Author(s) 2017. This article is an open access publication

\begin{abstract}
Summary In this post hoc analysis of the VITdAL-ICU study, an RCT in critically ill adults with 25-hydroxyvitamin D levels $\leq 20 \mathrm{ng} / \mathrm{ml}$, vitamin D3 did not have a significant effect on $\beta$-Crosslaps and osteocalcin.

Introduction Observational studies have shown accelerated bone loss in ICU survivors. A reversible contributor is vitamin D deficiency. In a post hoc analysis of the VITdAL-ICU study, we evaluated the effect of high-dose vitamin D3 on the bone turnover markers (BTM) $\beta$-Crosslaps (CTX) and osteocalcin (OC).

Methods The VITdAL-ICU study was a randomized, double-blind, placebo-controlled trial in critically ill adults with 25-hydroxyvitamin D levels $\leq 20 \mathrm{ng} / \mathrm{ml}$ who received placebo or high-dose vitamin D3 (a loading dose of 540,000 IU and starting 1 month after the loading dose five monthly maintenance doses of 90,000 IU). In this
\end{abstract}

K. Amrein

karin.amrein@medunigraz.at

1 Department of Internal Medicine, Division of Endocrinology and Diabetology, Medical University of Graz, Graz, Styria, Austria

2 Klinikum Klagenfurt am Wörthersee, Institute for Diagnostic and Interventional Radiology, Carinthia, Austria

3 Department of Neurology, Division of General Neurology, Medical University of Graz, Graz, Styria, Austria

4 Schilddrüsen|Endokrinologie|Osteoporose, Institut Dobnig GmbH, Graz, Styria, Austria

5 Department of Internal Medicine, LKH Hörgas-Enzenbach, Gratwein-Straßengel, Styria, Austria

6 The Nathan E. Hellman Memorial Laboratory, Division of Renal Medicine, Channing Division of Network Medicine, Brigham and Women's Hospital, Boston, MA, USA analysis on 289 survivors (209 telephone, 80 personal follow-up visits), BTM were analyzed on days $0,3,7$, 28 , and 180; self-reported falls and fractures were assessed. Bone mineral density (BMD) was measured after 6 months.

Results At baseline, CTX was elevated; OC was low in both groups - after 6 months, both had returned to normal. There were no differences between groups concerning BTM, BMD, falls, or fractures. In linear mixed effects models, CTX and OC showed a significant change over time ( $p<0.001$, respectively), but there was no difference between the vitamin $\mathrm{D}$ and placebo group ( $p=0.688$ and $p=0.972$, respectively).

Conclusions Vitamin D supplementation did not have a significant effect on BTM. Further studies should assess the effectiveness of vitamin D on musculoskeletal outcomes in ICU survivors.

Keywords Bone loss $\cdot$ Bone mineral density $\cdot$ Bone turnover markers $\cdot$ Critical illness $\cdot$ Fracture $\cdot$ Long-term outcomes · Osteoporosis · Vitamin D3

\section{Introduction}

In addition to underlying disease, critical illness per se seems to be detrimental to musculoskeletal health in various ways [1-3]: immobilization, inflammation, multiple endocrine alterations, hypercatabolism including muscle wasting, malnutrition, and certain drugs all have the potential to disturb the delicate balance between bone formation and bone resorption. Immobilization rapidly induces high bone turnover and bone loss in healthy adults and in patients following stroke with consecutive palsy [4, 5]. Inflammation-induced cytokines like TNF- $\alpha$ and IL-6 are elevated in critical illness [6], may reach 
extreme levels during sepsis, and induce bone resorption through osteoclastogenesis. Furthermore, hormonal and metabolic changes with adverse effects on bone that frequently affect critically ill patients include hypercortisolism, hypogonadism, hyposomatotropism, and secondary hypothyroidism besides alterations in calcium-phosphate metabolism and parathyroid hormone secretion [7, 8]. Finally, glucocorticoids, proton pump inhibitors, loop diuretics, and catecholamines may have negative effects on skeletal integrity [9-12]. Vitamin D deficiency also has negative consequences on musculoskeletal health [3].

Data on skeletal consequences of critical care including bone turnover, bone density, and fracture risk are limited. Under normal conditions, bone formation and bone resorption are tightly linked. In critical illness, however, marked uncoupling between osteoblast and osteoclast functions seems to be present [3]. A similar constellation is found in transplantation bone disease and glucocorticoid-induced osteoporosis, both conditions in which bone may be lost very rapidly accompanied by high fracture rates [12-14]. Bone resorption markers are high and increase further during intensive care unit (ICU) stay $[3,6,15,16]$ especially in sepsis [17] and following burn injuries $[18,19]$.

In 2011, a retrospective case-cohort study in 258 women and 481 men reported an increased fracture risk following critical illness; however, vitamin D status was not available in this study [20]. The same group recently demonstrated in a prospective observational study that bone loss in 66 patients was significantly greater in the year following ICU compared to controls from the Geelong Osteoporosis study [21].

More than a decade ago, Greet Van den Berghe et al. reported an effect of "high-dose" intravenous cholecalciferol supplementation (daily vitamin D supplement of \pm 500 IU vitamin D3) on bone turnover markers in prolonged critical illness [6]. Vitamin D slightly increased serum osteocalcin (OC) and diminished carboxy terminal propeptide type-I collagen; other bone turnover markers were not affected, however [6]. In patients with arterial hypertension and vitamin D deficiency no significant effect of vitamin $\mathrm{D}$ supplementation on bone turnover markers could be observed [22]. In older community-dwelling women, annual oral administration of high-dose cholecalciferol even resulted in an increased risk of falls and fractures [23]. Following heart transplantation, a higher rate of bone loss is associated with lower vitamin D serum levels [14]. Most importantly, vitamin D deficiency is one of the few modifiable risk factors for compromised skeletal health during and following critical illness. In addition, in their scientific opinion paper published in 2016, the European Food Safety Authority (EFSA) stated that "more research is needed to establish the relationship between responses of bone markers (e.g., OC, bone ALP, and urine N-telopeptide crosslinks) to changes in vitamin D status" [24]. Especially in light of the contradictory evidence published on vitamin D supplementation and BMD and fracture risk, more data on faster changing parameters than BMD and fracture development are of interest to detect more subtle effects of vitamin D on bone [24].

We therefore aimed to evaluate the effect of vitamin D supplementation on bone turnover markers in critical illness survivors as a primary outcome in a post hoc analysis of the VITdAL-ICU study, our recent phase III study evaluating the effect of high-dose vitamin D3 on hospital length of stay [25]. Further, we aimed to compare bone mineral density (BMD) and self-reported falls and fractures 6 months after an ICU stay in patients having received placebo versus patients having received vitamin D.

\section{Material and methods}

\section{Study design}

The detailed study design and methods as well as the results regarding the primary and secondary outcomes including hospital length of stay, length of ICU stay, the percentage of patients with 25-hydroxyvitamin D levels higher than $30 \mathrm{ng} / \mathrm{ml}$ at day 7 , hospital mortality, and 6-month mortality have been reported previously $[25,26]$. In brief, the VITdAL-ICU study was conducted at the Medical University of Graz, a large tertiary academic center in the southeast of Austria with 1538 beds including 123 ICU beds at five intensive care units ( 1 medical, 1 neurological, 3 surgical units). Adult patients who were expected to stay in the ICU $\geq 48 \mathrm{~h}$ were screened for vitamin D deficiency by measurement of serum $25(\mathrm{OH}) \mathrm{D}$ (measured with the IDS-iSYS, an assay based on chemiluminescence technology (Immunodiagnostic Systems, Boldon, UK)).

Major exclusion criteria were severely impaired gastrointestinal motility, pregnant or lactating women, hypercalcemia (total calcium $>2.65 \mathrm{mmol} / 1$ or ionized serum calcium $>1.35 \mathrm{mmol} / \mathrm{l}$ ), tuberculosis, sarcoidosis, or nephrolithiasis within the prior year.

In accordance with national and EU requirements and the principles of the Declaration of Helsinki [26], written informed consent was waived, delayed, or obtained from a legal surrogate, depending on the circumstances, and was obtained from each patient who regained mental capacity. The study had previously been registered at clinicaltrials.gov (Identifier: NCT01130181).

For the present analyses, only patients who had a 6-monthfollow-up - either a personal or a telephone visit-were included. 


\section{Randomization and intervention}

Patients were randomly assigned to either a "placebo" or "vitamin D" group in a 1:1 ratio, using the "Randomizer for Clinical Trials" tool developed at the Medical University of Graz (www.randomizer.at), stratified according to ICU type and gender. Patients randomized to the vitamin D group received a loading dose of 540,000 IU of vitamin D3 and starting 1 month after the loading dose, five monthly maintenance doses of 90,000 IU oral vitamin D3 or respective placebo. About $90 \%$ of patients in both groups did actually receive the monthly doses. All trial participants, investigators, and assessors were blinded. Patients of both treatment arms were allowed to receive standard vitamin D supplements via enteral and/or parenteral nutrition (approximately 200 IE per day) at the discretion of the treating physician.

\section{Outcomes and follow-up}

We followed all patients for 6 months, assessing among other variables bone turnover markers as well as the number of falls and fractures. BMD measurements were performed at the lumbar spine and femoral neck (Lunar iDXA®, GE) in the self-selected subgroup of patients who came for a follow-up visit after 6 months. Patients were free to choose personal $(n=80)$ or telephone $(n=210) 6$-month visits based on their preference.

\section{Laboratory analysis}

Blood and urine samples were collected on days $0,3,7,28$, and where feasible, month 6. OC and 3 -Crosslaps (CTX) levels were measured in all 289 patients at baseline and after 6 months in the 80 patients who agreed to a personal followup visit at our clinic. CTX levels were measured by electrochemiluminescence immunoassay (Cobas, Roche, Mannheim, Germany). Total serum OC was also measured by electrochemiluminescence immunoassay (Cobas, Roche) according to the manufacturer's instructions.

\section{Data management}

Investigators who were blinded to study-group assignments collected data. Only potential study drug-related adverse events (hypercalcemia, hypercalciuria, mortality, falls, fractures) were monitored and recorded within the 6-month follow-up.

\section{Statistical analysis}

Continuous data following a normal distribution are shown as means with standard deviations; parameters with a skewed distribution as medians with interquartile ranges and categorical data are presented as percentages. To compare between the vitamin D and placebo group at baseline, the unpaired Student t-test, the Mann-Whitney-U-test, or the chi-squared test were used. To evaluate changes in bone turnover markers over time and to compare changes in bone turnover markers between the vitamin $\mathrm{D}$ and the placebo group, a linear mixed effects model was calculated.

Where appropriate, skewed variables were $\ln$ transformed for parametric analyses. A two-sided $p$-value of less than 0.05 was considered significant. Analyses were performed with SAS, version 9.2, and SPSS, version 22.

\section{Funding}

The study was supported by the European Society for Clinical Nutrition and Metabolism (ESPEN), a research grant including provision of study medication from Fresenius Kabi (Germany) and the Austrian National Bank (ÖNB Jubiläumsfonds, Project Nr. 14,143). The funding sources had no influence on the design of the study, data analysis, or manuscript preparation.

\section{Results}

Two hundred eighty-nine of the patients recruited between May 2010 and March 2012 [25] had a follow-up visit after 6 months. Eighty patients presented personally in the outpatient clinic after 6 months, the other 209 survivors were evaluated by telephone. Reasons for not returning for a follow-up in person were of geographical nature and the patients' clinical conditions. Baseline demographic and clinical characteristics of the 289 patients according to vitamin D or placebo were comparable in the two groups (Table 1).

In linear mixed effects models, $25(\mathrm{OH}) \mathrm{D}$ showed a significant change over time $(p<0.001)$ and between the vitamin $\mathrm{D}$ and placebo group $(p<0.001) .1,25(\mathrm{OH}) \mathrm{D}$ showed a significant change over time $(p<0.001)$, but not between groups ( $p=0.148$ ), as did total calcium (over time: $p<0.001$; between groups: $p=0.365$ ), ionized calcium (over time: $p<0.001$; between groups: $p=0.242$ ), urinary calcium/ creatinine-ratio (over time: $p<0.001$; between groups: $p=0.409$ ), as well as CTX (over time: $p<0.001$; between groups: $p=0.688$ )—which decreased-or OC (over time: $p<0.001$; between groups: $p=0.972$ ) — which increased. Despite the significant increase, OC remained within normal levels. Sclerostin also showed a significant change over time ( $p=0.016)$, but not between groups $(p=0.140)$.

There was, however, a significant difference over time as well as between groups for phosphate (over time: $p=0.011$; between groups: $p=0.030$ ) and parathyroid hormone (over time: $p<0.001$; between groups: $p=0.038$ ) Table 2 . 
Table 1 Characteristics of the study population with available followup data $(n=289)$

\begin{tabular}{lll}
\hline & $\begin{array}{l}\text { Placebo } \\
(n=136)\end{array}$ & $\begin{array}{l}\text { Vitamin D } \\
(n=153)\end{array}$ \\
\hline Age, years & $62.2 \pm 14.5$ & $60.3 \pm 16.3$ \\
Female, $n(\%)$ & $51(37.5 \%)$ & $54(35.3 \%)$ \\
Body mass index, kg/m ${ }^{2}$ & $27.5 \pm 6.0$ & $27.8 \pm 5.1$ \\
Charlson comorbidity index & $2.8 \pm 2.2$ & $2.6 \pm 2.2$ \\
SAPS II at ICU admission & $24.9 \pm 19.1$ & $21.7 \pm 17.1$ \\
TISS-28 at study inclusion & $36.9 \pm 7.6$ & $36.8 \pm 7.3$ \\
Admission diagnosis, $n(\%)$ & & $12(7.8 \%)$ \\
$\quad$ Sepsis & $11(8.1 \%)$ & $18(11.8 \%)$ \\
Cardiovascular & $21(15.4 \%)$ & $38(24.8 \%)$ \\
$\quad$ Neurologic & $32(23.5 \%)$ & $15(9.9 \%)$ \\
Other non-surgical & $15(11.1 \%)$ & $29(19.0 \%)$ \\
Cardiosurgical & $25(18.4 \%)$ & $20(13.1 \%)$ \\
Trauma & $14(10.3 \%)$ & $21(13.9 \%)$ \\
$\quad$ Other surgical & $18(13.2 \%)$ & \\
At study inclusion & & $114(74.5 \%)$ \\
$\quad$ Mechanical ventilation, $n(\%)$ & $100(73.5 \%)$ & $82(53.6 \%)$ \\
$\quad$ Norepinephrine use, $n(\%)$ & $73(53.7 \%)$ & \\
\hline
\end{tabular}

Notes: Plus-minus values are means \pm SD. The Charlson comorbidity index predicts 10 -year mortality and is a sum calculated from 22 comorbid conditions with each assigned a score of 1, 2, 3, or 6. The Simplified Acute Physiology Score (SAPS II) is a point score measuring the severity of disease for patients admitted to the intensive care unit. It is calculated from 12 routine physiological measurements and ranges from 0 to 163 with higher scores indicating higher disease severity. Therapeutic Intervention Scoring System (TISS) measures the extent of nursing workload with a maximum TISS-28 score of 78 . A higher score indicates a higher nursing workload

Abbreviations: $I C U$ intensive care unit

Two clinical fractures occurred in each group within 6 months (spine X-rays were not performed at follow-up). Rates of self-reported falls at 6 months were numerically higher in the placebo group $(33 / 136,24.3 \%$, in the placebo group vs. $27 / 153,17.7 \%$, in the vitamin $\mathrm{D}$ group, $p=0.17$ ), this difference was not statistically significant though.

Six months after ICU admission, BMD at the lumbar spine and femoral neck was not significantly different in the vitamin D group compared to the placebo group (Table 3). In the severe and less severe vitamin D deficiency subgroups, there was also no significant difference in BMD between the vitamin D and the placebo group. After 6 months, 42\% (33/79) of patients were classified as osteopenic, and 13\% (10/79) as osteoporotic by osteodensitometry.

\section{Discussion}

In this post hoc analysis of a prospective RCT in critically ill patients with 25 -hydroxyvitamin D levels $\leq 20 \mathrm{ng} / \mathrm{ml}$ receiving high-dose vitamin D3 or placebo, we found no significant differences in bone turnover markers, BMD, fractures, and falls within 6 months after ICU admission between groups. Furthermore, we observed no significant effect of vitamin D supplementation on CTX and OC. There was, however, a significant increase of OC and a significant decrease of CTX after 6 months compared to baseline suppressed OC and elevated CTX in both study groups.

Besides vitamin D deficiency, other detrimental factors affecting skeletal health in this specific population include immobilization, rapid muscle loss during immobilization, inflammation, endocrine alterations, hypercatabolism, malnutrition, and drugs. All these factors likely contribute to increased bone resorption and accelerated bone loss as indicated by elevated CTX. Especially elderly ICU survivors also seem to carry an increased fracture risk, as suggested by the available limited clinical data [20]. This is highly relevant as fragility fractures, especially hip fractures, are deleterious events for an individual leading to decreased quality of life and often the loss of independence even in less vulnerable populations [27-29].

To overcome this situation of increased bone resorption and impaired skeletal health, Hollander and Mechanick suggested the consideration of intravenous bisphosphonates to potently decrease bone resorption [2]. They have been studied in small trials in critically ill adults and children and showed promising results [30-32]. Two recent retrospective observational studies suggested that preadmission bisphosphonate use in critically ill patients may even be associated with increased survival $[33,34]$.

The fact that no clear-cut difference was found in BMD after 6 months between patients receiving vitamin $\mathrm{D}$ and those receiving placebo might be attributed to the small sample size available for DXA after 6 months and the slow changes in BMD over time. Due to the nature of the investigated population, DXA scans were not performed at baseline. Furthermore, other factors such as immobilization and muscle loss as well as negative energy balances might have a stronger influence on BMD than vitamin D status alone. In view of the aging ICU population [35], the risk of critical illness-related falls and fractures could be substantial, an aggressive multidisciplinary approach may be indicated to reduce morbidity, mortality, and the high costs that have been documented in other, less sick populations [36-38].

Our data support the findings by Orford et al. [21], showing increased bone resorption during acute immobilization and improvement after recovery from critical illness. Similar to Orford, our patients showed a significant increase of OC after critical illness back to normal levels, but no commensurate response as a compensatory increase in bone formation.

In addition to limiting muscle loss by avoiding a negative energy balance, treatment of vitamin D deficiency with the 


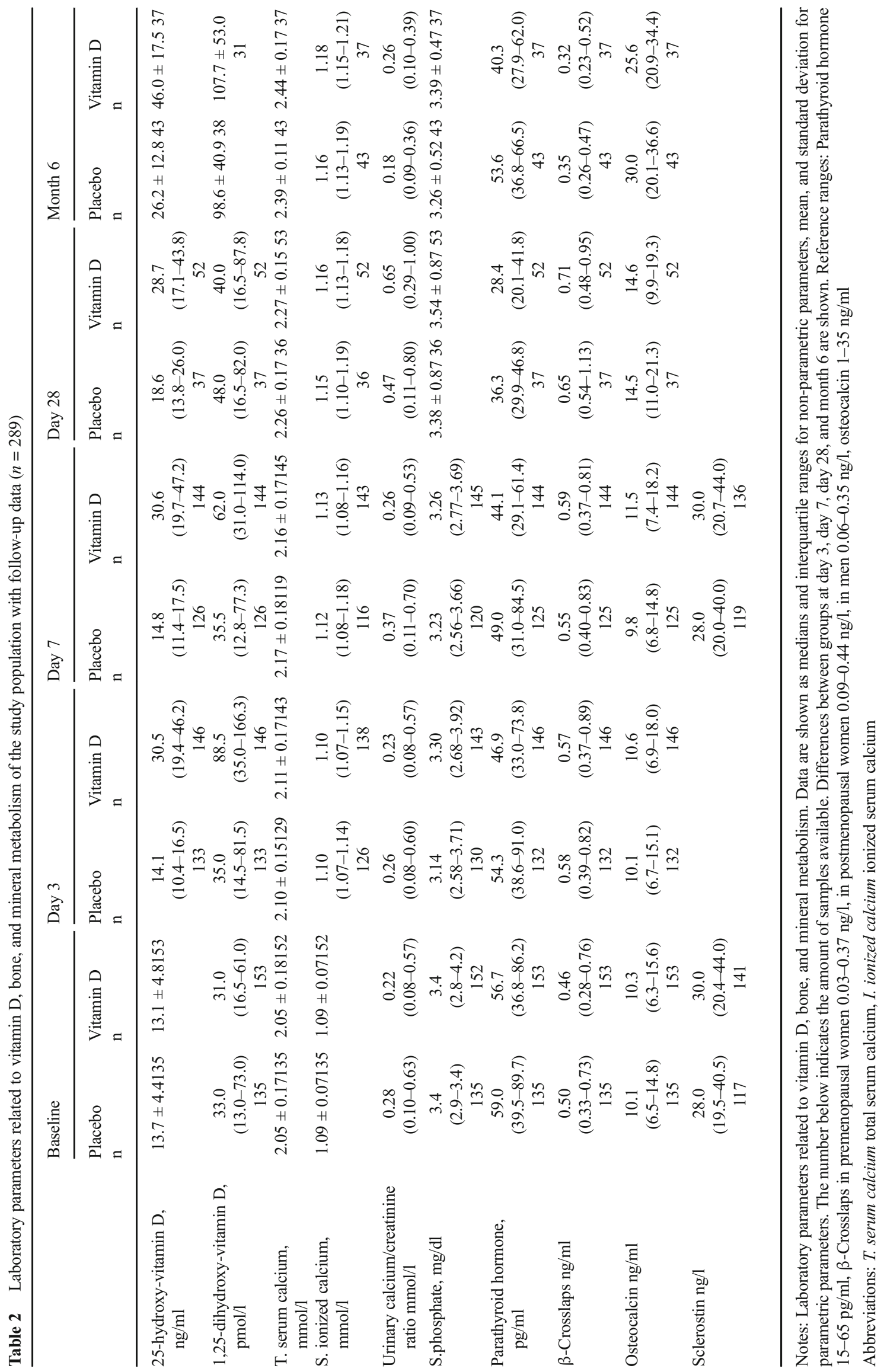


Table 3 Six-month follow-up

\begin{tabular}{|c|c|c|c|c|c|c|c|c|c|}
\hline & \multirow{2}{*}{\multicolumn{2}{|c|}{ Total study population }} & \multirow[b]{3}{*}{$P$-value } & \multicolumn{5}{|c|}{ Prespecified Subgroup Population } & \multirow[b]{3}{*}{$P$-value } \\
\hline & & & & \multicolumn{2}{|c|}{$\begin{array}{l}\text { Severe vitamin D } \\
\text { deficiency }^{a}\end{array}$} & \multirow[b]{2}{*}{$P$-value } & \multicolumn{2}{|c|}{$\begin{array}{l}\text { Less severe vitamin D } \\
\text { deficiency }{ }^{\mathrm{b}}\end{array}$} & \\
\hline & Placebo & Vitamin D & & Placebo & Vitamin D & & Placebo & Vitamin D & \\
\hline Falls, number & $33(24.3 \%)$ & $27(17.7 \%)$ & 0.108 & $14(27.5 \%)$ & $16(25.0 \%)$ & 0.465 & $19(22.4 \%)$ & $11(12.4 \%)$ & 0.061 \\
\hline Fractures, number & $2(1.5 \%)$ & $2(1.3 \%)$ & - & $1(2.0 \%)$ & $1(1.6 \%)$ & - & $1(1.2 \%)$ & $1(1.1 \%)$ & - \\
\hline \multicolumn{10}{|l|}{ BMD, t-score } \\
\hline Lumbar spine & $-0.57 \pm 1.30$ & $-0.16 \pm 1.49$ & 0.207 & $-0.22 \pm 1.42$ & $-0.23 \pm 1.30$ & 0.980 & $-0.75 \pm 1.23$ & $-0.12 \pm 1.60$ & 0.133 \\
\hline Femoral neck & $-0.88 \pm 1.03$ & $-0.86 \pm 1.31$ & 0.949 & $\begin{array}{l}-0.70 \\
\quad(-1.0 \text { to } 0.0)\end{array}$ & $\begin{array}{l}-1.05 \\
\quad(-1.83 \text { to } 0.08)\end{array}$ & 0.635 & $-0.96 \pm 0.88$ & $-0.85 \pm 1.34$ & 0.740 \\
\hline Timed up and go test & $10(8-14)$ & $10(8-12)$ & 0.304 & $10(8-14)$ & $11(9-14)$ & 0.650 & $9(8-13)$ & $8.5(7-10.3)$ & 0.105 \\
\hline
\end{tabular}

Notes: Data are shown as medians and interquartile ranges for non-parametric parameters, mean and standard deviation for parametric parameters. Bone mineral density was tested at the lumbar spine and the femoral neck with dual energy X-ray absorptiometry (Lunar iDXA®, GE). BMD was assessed at a personal 6-month follow-up visit at the study site, the remaining endpoints were assessed at personal 6-month follow-up visits either at the study site or via telephone in surviving patients. The timed up and go test is a simple test used to assess a person's mobility, 10 points indicating normal mobility, $11-$ 20 points indicating normal limits for frail elderly and disabled patients, more than 20 seconds implying that the person is in need of assistance. Severe vitamin $\mathrm{D}$ deficiency $=25$-hydroxyvitamin $\mathrm{D}$ level at study inclusion $\leq 12 \mathrm{ng} / \mathrm{ml}$, less severe vitamin $\mathrm{D}$ deficiency $=25$-hydroxyvitamin $\mathrm{D}$ level at study inclusion $>12 \mathrm{ng} / \mathrm{ml}$

Abbreviations: $B M D$ bone mineral density

aim to reach levels considered necessary for optimal bone health in other populations (above $20 \mathrm{ng} / \mathrm{ml}$ ) [39] might be one easily adoptable treatment to improve skeletal consequences of prolonged critical illness. In the present study, however, we could not observe a significant effect of vitamin D supplementation on bone turnover markers. The development of suitable - currently unavailable - parenteral vitamin D monopreparations might contribute to more predictable increases in serum 25(OH)D levels [40], as critical illnessassociated impaired gastrointestinal function or renal and drug-related compromises of the hepatic CYP450 system necessary for 25-hydroxylation of vitamin D might impair vitamin D uptake [41, 42].

There are important limitations to our study. These are the single center design, the lack of non-Caucasian or pediatric subjects, possibly limiting the generalizability of our findings and the relatively short follow-up for the outcome fractures, which were - as was the occurrence of fallsself-reported. Further, our trial was certainly underpowered for smaller effects, and spine X-rays detecting clinically silent vertebral fractures were not performed. Also, we did not evaluate how many patients were and were not able to ambulate before study inclusion and how many needed walking aids before and after the study, information that might be important regarding the impact of immobilization on bone turnover markers. Lacking information on nitrogen metabolism and balance and its association with bone turnover is another limitation of our study.
In conclusion, we observed increased bone resorption and decreased bone formation in critically ill patients with 25 hydroxyvitamin D levels $\leq 20 \mathrm{ng} / \mathrm{ml}$, both conditions resolving over a follow-up period of 6 months. Vitamin D supplementation had no significant effect on CTX and OC. However, further studies are necessary to evaluate the relationship between vitamin $\mathrm{D}$ supplementation and $\mathrm{BTM}, \mathrm{BMD}$, and fracture risk in critically ill individuals with overt vitamin D deficiency. Perhaps a beneficial effect of vitamin $D$ in critically ill patients may only be present in patients with very low vitamin $\mathrm{D}$ status, or a beneficial effect of vitamin $\mathrm{D}$ on bone health in critically ill patients might be entirely lacking.

Acknowledgements Open access funding provided by Medical University of Graz. We would like to express our gratitude to the staff of the participating ICUs, to patients, relatives, family physicians, health care workers in other institutions and caregivers who made this trial possible. We also would like to acknowledge the support of Wolfgang Wolowszczuk for the sclerostin analyses.

\section{Compliance with ethical standards}

Funding Karin Amrein and Harald Dobnig report grants from European Society for Clinical Nutrition and Metabolism (ESPEN), grants, lecture fees, and non-financial support from Fresenius Kabi (Germany), and a grant from the Austrian National Bank (Jubiläumsfonds) during the conduct of the study.

Conflicts of interest None of the authors is in any regards financially dependent on the named institutions. 
Open Access This article is distributed under the terms of the Creative Commons Attribution-NonCommercial 4.0 International License (http:// creativecommons.org/licenses/by-nc/4.0/), which permits any noncommercial use, distribution, and reproduction in any medium, provided you give appropriate credit to the original author(s) and the source, provide a link to the Creative Commons license, and indicate if changes were made.

\section{References}

1. Griffith DM, Walsh TS (2011) Bone loss during critical illness: a skeleton in the closet for the intensive care unit survivor? Crit Care Med 39:1554-1556

2. Hollander JM, Mechanick JI (2009) Bisphosphonates and metabolic bone disease in the ICU. Curr Opin Clin Nutr Metab Care 12: 190-195

3. Via MA, Gallagher EJ, Mechanick JI (2010) Bone physiology and therapeutics in chronic critical illness. Ann N Y Acad Sci 1211:85-94

4. Rittweger J, Frost HM, Schiessl H, Ohshima H, Alkner B, Tesch P, Felsenberg D (2005) Muscle atrophy and bone loss after 90 days' bed rest and the effects of flywheel resistive exercise and pamidronate: results from the LTBR study. Bone 36:1019-1029

5. Gaudio A, Pennisi P, Bratengeier C, Torrisi V, Lindner B, Mangiafico RA, Pulvirenti I, Hawa G, Tringali G, Fiore CE (2010) Increased sclerostin serum levels associated with bone formation and resorption markers in patients with immobilizationinduced bone loss. J Clin Endocrinol Metab 95:2248-2253

6. Van den Berghe G, Van Roosbroeck D, Vanhove P, Wouters PJ, De Pourcq L, Bouillon R (2003) Bone turnover in prolonged critical illness: effect of vitamin D. J Clin Endocrinol Metab 88:4623-4632

7. Vanhorebeek I, Langouche L, Van den Berghe G (2006) Endocrine aspects of acute and prolonged critical illness. Nat Clin Pract Endocrinol Metab 2:20-31

8. Kelly A, Levine MA (2013) Hypocalcemia in the critically ill patient. J Intensive Care Med 28:166-177

9. Fraser LA, Leslie WD, Targownik LE, Papaioannou A, Adachi JD, CaMos Research Group (2013) The effect of proton pump inhibitors on fracture risk: report from the Canadian multicenter osteoporosis study. Osteoporos Int 24:1161-1168

10. Veldhuis-Vlug AG, El Mahdiui M, Endert E, Heijboer AC, Fliers E, Bisschop PH (2012) Bone resorption is increased in pheochromocytoma patients and normalizes following adrenalectomy. J Clin Endocrinol Metab 97:E2093-E2097

11. Walsh JS, Newman C, Eastell R (2012) Heart drugs that affect bone. Trends Endocrinol Metab 23:163-168

12. Silverman SL, Lane NE (2009) Glucocorticoid-induced osteoporosis. Curr Osteoporos Rep 7:23-26

13. Kulak CA, Borba VZ, Kulak Junior J, Campos DJ, Shane E (2010) Post-transplantation osteoporosis. Arq Bras Endocrinol Metabol 54:143-149

14. Shane E, Rivas M, McMahon DJ, Staron RB, Silverberg SJ, Seibel MJ, Mancini D, Michler RE, Aaronson K, Addesso V, Lo SH (1997) Bone loss and turnover after cardiac transplantation. J Clin Endocrinol Metab 82:1497-1506

15. Nierman DM, Mechanick JI (1998) Bone hyperresorption is prevalent in chronically critically ill patients. Chest 114:1122-1128

16. Shapses SA, Weissman C, Seibel MJ, Chowdhury HA (1997) Urinary pyridinium cross-link excretion is increased in critically ill surgical patients. Crit Care Med 25:85-90
17. Smith LM, Cuthbertson B, Harvie J, Webster N, Robins S, Ralston SH (2002) Increased bone resorption in the critically ill: association with sepsis and increased nitric oxide production. Crit Care Med 30: $837-840$

18. Leblebici B, Sezgin N, Ulusan SN, Tarim AM, Akman MN, Haberal MA (2008) Bone loss during the acute stage following burn injury. J Burn Care Res 29:763-767

19. Muschitz GK, Schwabegger E, Kocijan R, Baierl A, Moussalli H, Fochtmann A, Nickl S, Tinhofer I, Haschka J, Resch H, Rath T, Pietschmann P, Muschitz C (2016) Early and sustained changes in bone metabolism after severe burn injury. J Clin Endocrinol Metab 101:1506-1515

20. Orford NR, Saunders K, Merriman E, Henry M, Pasco J, Stow P, Kotowicz M (2011) Skeletal morbidity among survivors of critical illness. Crit Care Med 39:1295-1300

21. Orford NR, Lane SE, Bailey M, Pasco JA, Cattigan C, Elderkin T, Brennan-Olsen SL, Bellomo R, Cooper DJ, Kotowicz MA (2016) Changes in bone mineral density in the year after critical illness. Am J Respir Crit Care Med 193:736-744

22. Schwetz V, Trummer C, Pandis M, Grubler MR, Verheyen N, Gaksch M, Zittermann A, Marz W, Aberer F, Lang A, Treiber G, Friedl C, Obermayer-Pietsch B, Pieber TR, Tomaschitz A, Pilz S (2017) Effects of vitamin D supplementation on bone turnover markers: a randomized controlled trial. Nutrients 9: https://doi. org/10.3390/nu9050432

23. Sanders KM, Stuart AL, Williamson EJ, Simpson JA, Kotowicz MA, Young D, Nicholson GC (2010) Annual high-dose oral vitamin $\mathrm{D}$ and falls and fractures in older women: a randomized controlled trial. JAMA 303:1815-1822

24. EFSA Panel on Dietetic Products, Nutrition and Allergies (NDA) (2016) Dietary reference values for vitamin D. EFSA J 14(10):4547

25. Amrein K, Schnedl C, Holl A, Riedl R, Christopher KB, Pachler C, Urbanic Purkart T, Waltensdorfer A, Munch A, Warnkross H, Stojakovic T, Bisping E, Toller W, Smolle KH, Berghold A, Pieber TR, Dobnig H (2014) Effect of high-dose vitamin D3 on hospital length of stay in critically ill patients with vitamin D deficiency: the VITdAL-ICU randomized clinical trial. JAMA 312: $1520-1530$

26. Amrein K, Schnedl C, Berghold A, Pieber TR, Dobnig H (2012) Correction of vitamin D deficiency in critically ill patients VITdAL@ICU study protocol of a double-blind, placebocontrolled randomized clinical trial. BMC Endocr Disord 12:27, 6823-12-27

27. Edwards BJ, Song J, Dunlop DD, Fink HA, Cauley JA (2010) Functional decline after incident wrist fractures-study of osteoporotic fractures: prospective cohort study. BMJ 341:c3324

28. Papaioannou A, Kennedy CC, Ioannidis G, Sawka A, Hopman WM, Pickard L, Brown JP, Josse RG, Kaiser S, Anastassiades T, Goltzman D, Papadimitropoulos M, Tenenhouse A, Prior JC, Olszynski WP, Adachi JD, CaMos Study Group (2009) The impact of incident fractures on health-related quality of life: 5 years of data from the Canadian multicentre osteoporosis study. Osteoporos Int 20:703-714

29. Pasco JA, Sanders KM, Hoekstra FM, Henry MJ, Nicholson GC, Kotowicz MA (2005) The human cost of fracture. Osteoporos Int 16:2046-2052

30. Klein GL, Wimalawansa SJ, Kulkarni G, Sherrard DJ, Sanford AP, Herndon DN (2005) The efficacy of acute administration of pamidronate on the conservation of bone mass following severe burn injury in children: a double-blind, randomized, controlled study. Osteoporos Int 16:631-635 
31. Nierman DM, Mechanick JI (2000) Biochemical response to treatment of bone hyperresorption in chronically critically ill patients. Chest 118:761-766

32. Via MA, Potenza MV, Hollander J, Liu X, Peng Y, Li J, Sun L, Zaidi M, Mechanick JI (2012) Intravenous ibandronate acutely reduces bone hyperresorption in chronic critical illness. J Intensive Care Med 27:312-318

33. Lee P, Ng C, Slattery A, Nair P, Eisman JA, Center JR (2016) Preadmission bisphosphonate and mortality in critically ill patients. J Clin Endocrinol Metab 101:1945-1953

34. Schulman RC, Moshier EL, Rho L, Casey MF, Godbold JH, Zaidi M, Mechanick JI (2016) Intravenous Pamidronate is associated with reduced mortality in patients with chronic critical illness. Endocr Pract 22:799-808

35. Nguyen YL, Angus DC, Boumendil A, Guidet B (2011) The challenge of admitting the very elderly to intensive care. Ann intensive care 1:n5820-1-29

36. Kanis JA, Oden A, Johnell O, De Laet C, Jonsson B, Oglesby AK (2003) The components of excess mortality after hip fracture. Bone $32: 468-473$

37. Center JR, Nguyen TV, Schneider D, Sambrook PN, Eisman JA (1999) Mortality after all major types of osteoporotic fracture in men and women: an observational study. Lancet 353:878-882

38. Haentjens P, Magaziner J, Colon-Emeric CS, Vanderschueren D, Milisen K, Velkeniers B, Boonen S (2010) Meta-analysis: excess mortality after hip fracture among older women and men. Ann Intern Med 152:380-390

39. Ross AC, Manson JE, Abrams SA, Aloia JF, Brannon PM, Clinton SK, Durazo-Arvizu RA, Gallagher JC, Gallo RL, Jones G, Kovacs CS, Mayne ST, Rosen CJ, Shapses SA (2011) The 2011 report on dietary reference intakes for calcium and vitamin $\mathrm{D}$ from the Institute of Medicine: what clinicians need to know. J Clin Endocrinol Metab 96:53-58

40. Vanek VW, Borum P, Buchman A, Fessler TA, Howard L, Jeejeebhoy K, Kochevar M, Shenkin A, Valentine CJ, Novel Nutrient Task Force, Parenteral Multi-Vitamin and Multi-Trace Element Working Group, American Society for Parenteral and Enteral Nutrition (A.S.P.E.N.) Board of Directors (2012) A.S.P.E.N. Position paper: recommendations for changes in commercially available parenteral multivitamin and multi-trace element products. Nutr Clin Pract 27:440-491

41. Spriet I, Meersseman W, de Hoon J, von Winckelmann S, Wilmer A, Willems L (2009) Mini-series: II. Clinical aspects. Clinically relevant CYP450-mediated drug interactions in the ICU. Intensive Care Med 35:603-612

42. Michaud J, Naud J, Ouimet D, Demers C, Petit JL, Leblond FA, Bonnardeaux A, Gascon-Barre M, Pichette V (2010) Reduced hepatic synthesis of calcidiol in uremia. J Am Soc Nephrol 21:14881497 